\title{
Leptin-dependent neuronal NO signaling in the preoptic hypothalamus facilitates reproduction
}

\author{
Nicole Bellefontaine,1,2 Konstantina Chachlaki,,1,2 Jyoti Parkash,1,2 Charlotte Vanacker,1,2 \\ William Colledge, ${ }^{3}$ Xavier d'Anglemont de Tassigny, ${ }^{3}$ John Garthwaite, ${ }^{4}$ \\ Sebastien G. Bouret, ${ }^{1,2,5}$ and Vincent Prevot ${ }^{1,2}$ \\ ${ }^{1}$ Inserm, Jean-Pierre Aubert Research Centre, U837, Development and Plasticity of the Postnatal Brain, Lille, France. \\ 2Université du Droit et de la Santé de Lille, University Lille Nord de France, School of Medicine, Lille, France. \\ ${ }^{3}$ Department of Physiology, Development, and Neuroscience, University of Cambridge, Cambridge, United Kingdom. \\ ${ }^{4}$ The Wolfson Institute for Biomedical Research, University College London, London, United Kingdom. ${ }^{5}$ Developmental Neuroscience Program, \\ The Saban Research Institute, Children's Hospital Los Angeles, University of Southern California, Los Angeles, California, USA.
}

\begin{abstract}
The transition to puberty and adult fertility both require a minimum level of energy availability. The adipocyte-derived hormone leptin signals the long-term status of peripheral energy stores and serves as a key metabolic messenger to the neuroendocrine reproductive axis. Humans and mice lacking leptin or its receptor fail to complete puberty and are infertile. Restoration of leptin levels in these individuals promotes sexual maturation, which requires the pulsatile, coordinated delivery of gonadotropin-releasing hormone to the pituitary and the resulting surge of luteinizing hormone (LH); however, the neural circuits that control the leptin-mediated induction of the reproductive axis are not fully understood. Here, we found that leptin coordinated fertility by acting on neurons in the preoptic region of the hypothalamus and inducing the synthesis of the freely diffusible volume-based transmitter NO, through the activation of neuronal NO synthase (nNOS) in these neurons. The deletion of the gene encoding nNOS or its pharmacological inhibition in the preoptic region blunted the stimulatory action of exogenous leptin on LH secretion and prevented the restoration of fertility in leptin-deficient female mice by leptin treatment. Together, these data indicate that leptin plays a central role in regulating the hypothalamo-pituitary-gonadal axis in vivo through the activation of nNOS in neurons of the preoptic region.
\end{abstract}

\section{Introduction}

Reproduction in mammals is favored when there is sufficient energy available to permit the survival of offspring. Minimum energy stores are thus necessary for the initiation of puberty and the maintenance of reproductive capacity. Consequently, undernourishment is associated with delays in sexual maturation and the suppression of fertility during adulthood. At the other end of the spectrum, the rising prevalence of metabolic disorders involving excess energy stores, including obesity, has been linked with a rise in the incidence of precocious puberty, abnormal menstrual cycles, and infertility $(1,2)$. Given this alarming increase in metabolic disorders and their association with conditions such as infertility, a great deal of research has been devoted to elucidating the mechanisms underlying these disorders and their relationship to the neuroendocrine reproductive axis (3). Leptin, an adipocytederived hormone secreted in proportion to body fat mass, has been linked to the regulation of both metabolic and reproductive function. Chronically elevated leptin levels, both a characteristic of obesity and a condition known to accelerate puberty $(4,5)$ and prolong the menstrual cycle (5), may indeed account for the increased prevalence of reproductive impairment in obese patients.

Leptin deficiency, caused by the Lep ${ }^{o b / o b}$ loss-of-function mutation in both humans and rodents, results in obesity, a failure to complete puberty, and consequently, infertility $(6,7)$. Chronic lep-

Conflict of interest: The authors have declared that no conflict of interest exists. Citation for this article: J Clin Invest. 2014;124(6):2550-2559. doi:10.1172/JCI65928. tin administration to $L e p^{o b / o b}$ individuals induces the completion of sexual maturation and the restoration of fertility, indicating the key role played by leptin $(7,8)$. There is compelling evidence to suggest that leptin regulates neurons producing gonadotropinreleasing hormone (GnRH neurons) via cells afferent to these neurons $(9,10)$ and/or those that interact morphologically with them (11). However, despite leptin's crucial implications for mammalian reproduction, the identification of the sites of action and specific cell populations involved in the transmission of leptin signaling to the neuroendocrine reproductive axis remains elusive. In this report, we show that neurons synthesizing NO could act as mediators of leptin signaling to the central reproductive axis and identify the preoptic region as a novel site for the integration of this signal into $\mathrm{GnRH}$ neuronal function.

\section{Results}

Leptin activates a subset of NO-synthesizing neurons in the preoptic region of the hypothalamus. NO is known to play an important role in the neuroendocrine control of reproduction $(12,13)$ and has been implicated directly in the regulation of GnRH neuronal activity (14). $\mathrm{NO}$ is produced in the vicinity of GnRH-containing perikarya in the preoptic region by neuronal NO synthase-expressing (nNOSexpressing) neurons (14), which we have shown recently to be an integral part of the neuronal network controlling ovarian cyclicity and ovulation (15). Whether, in addition to being a trigger for the preovulatory activation of GnRH neurons, these nNOS neurons are also able to sense signals required for the maturation and function 
A

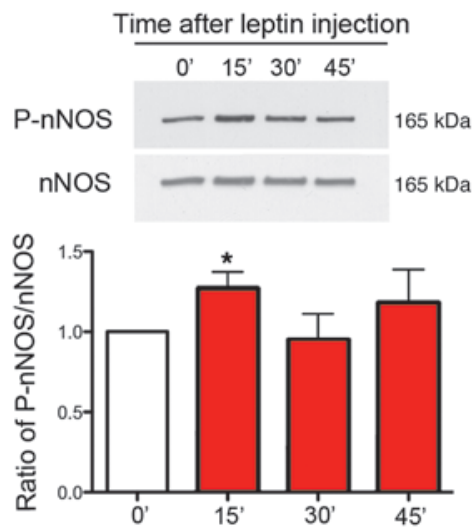

C

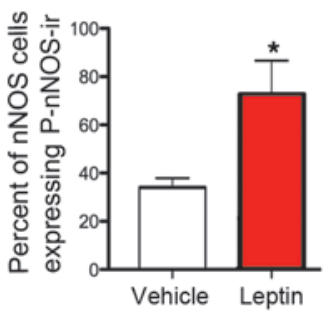

D

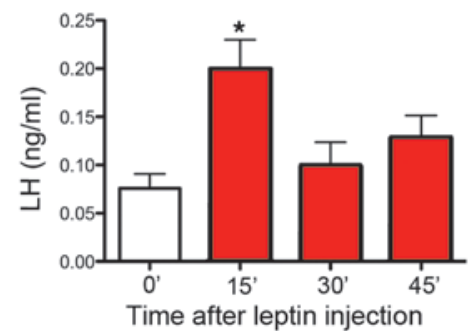

B
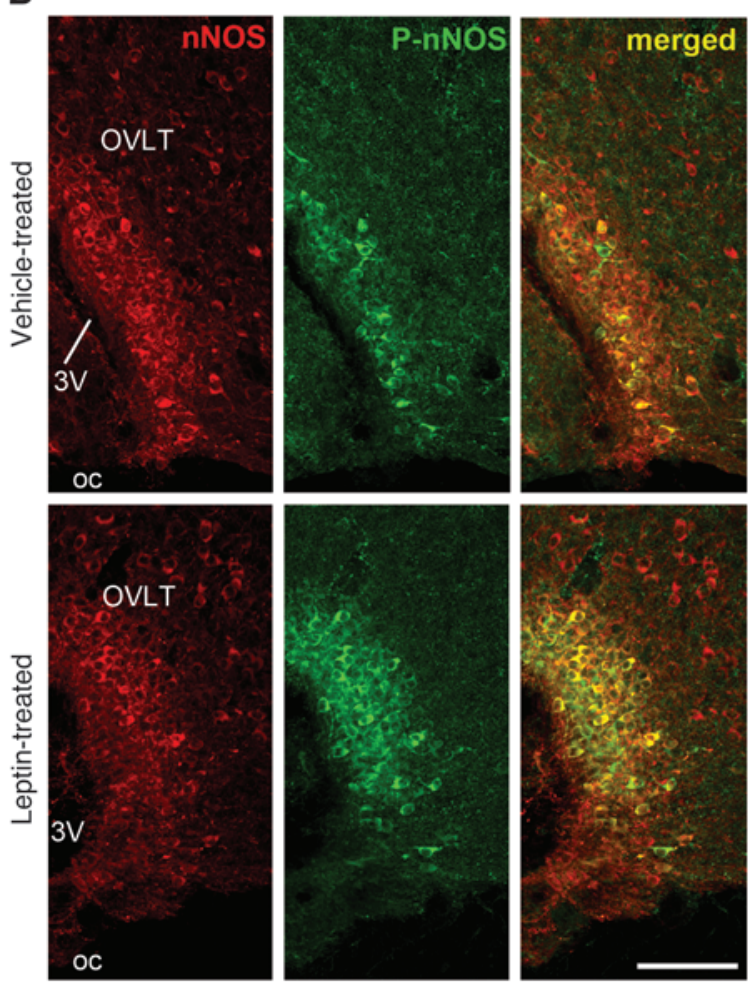

\section{Figure 1}

Leptin activates nNOS in the preoptic region and increases circulating LH levels. (A) Representative Western blots for phosphorylated and total nNOS at the times indicated (in minutes) following leptin treatment (see Supplemental Figure 4 for full-length photographs of the Western blots). Leptin promotes the phosphorylation of nNOS acutely at 15 minutes. (B) Coronal sections of the OVLT, showing an increase in the percentage of nNOS cells expressing P-nNOS immunoreactivity (ir) 15 minutes after leptin stimulation. 3V, third ventricle; oc, optic chiasm. Scale bar: 100 um. (C) Quantification of immunolabeling shown in B. (D) Circulating LH levels surge 15 minutes after leptin administration. ${ }^{*} P<0.05$.

of the reproductive axis, such as leptin, is not known. The mapping of leptin-responsive cells in the hypothalamus has revealed that several leptin receptor (LepR) populations are NO-synthesizing neurons $(16,17)$ and that the enzymatic activity of nNOS can be regulated by leptin in rostral areas of the hypothalamus (16). To examine whether nNOS neurons within the preoptic region are leptin sensitive, we performed double immunofluorescence analyses for nNOS and the leptin-induced phosphorylation of STAT3 (P-STAT3), a widely used technique for identifying leptin-responsive cells (18). In cycling diestrous mice, $30 \%-40 \%$ of NO-synthesizing neurons in the dorsal part of the medial preoptic area (MEPO) and the organum vasculosum of the lamina terminalis (OVLT) were shown to express P-STAT3 (Supplemental Figure 1; supplemental material available online with this article; doi:10.1172/JCI65928DS1). We next investigated the putative effect of leptin treatment on nNOS activity by studying its state of phosphorylation (19). Interestingly, Western blot analyses showed an acute increase in phosphorylated nNOS (P-nNOS) expression in the preoptic region of diestrous mice 15 minutes after leptin injection (Figure 1A). The phospho- rylation of nNOS was found to be restricted to the OVLT and the MEPO, in which $80 \%$ of nNOS-expressing cells displayed P-nNOS immunoreactivity following leptin injection (Figure 1, B and C) ( $n=4, P<0.05$, Student's $t$ test for vehicle vs. leptin treatment). Leptin-induced nNOS phosphorylation in these neurons coincided with a rise in luteinizing hormone (LH) levels from their nadir (Figure 1 , A and D) $(n=5, P<0.05,1$-way ANOVA). Together, these results suggest that nNOS neurons within and in direct proximity to the OVLT, a site devoid of the blood-brain barrier (20) and to which GnRH neurons extend dendrites (21), may acutely sense changes in leptin levels and rapidly relay this information to $\mathrm{GnRH}$ neurons, which in turn stimulate LH release.

NO signaling originating from the preoptic region is important for leptininduced LH release and is independent of kisspeptin/GPR54 signaling. Hypothalamic neurons that release the neuropeptide kisspeptin, a fundamental player in the reproductive axis (22-24), functionally interact with nNOS neurons (which express the kisspeptin receptor GPR54) within the preoptic region to regulate $\mathrm{GnRH} / \mathrm{LH}$ release (15). Kisspeptin neurons in the arcuate nucleus (ARH) puta- 
A

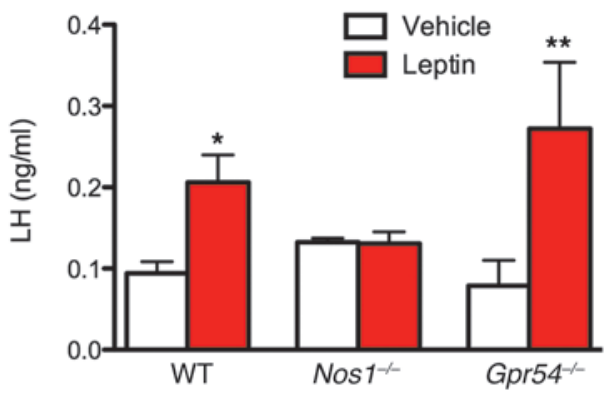

B
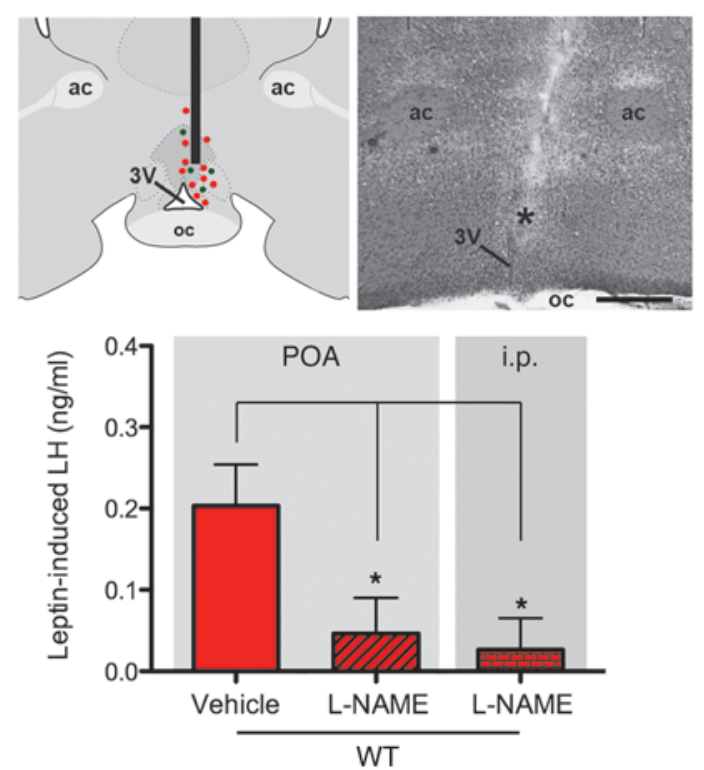

C
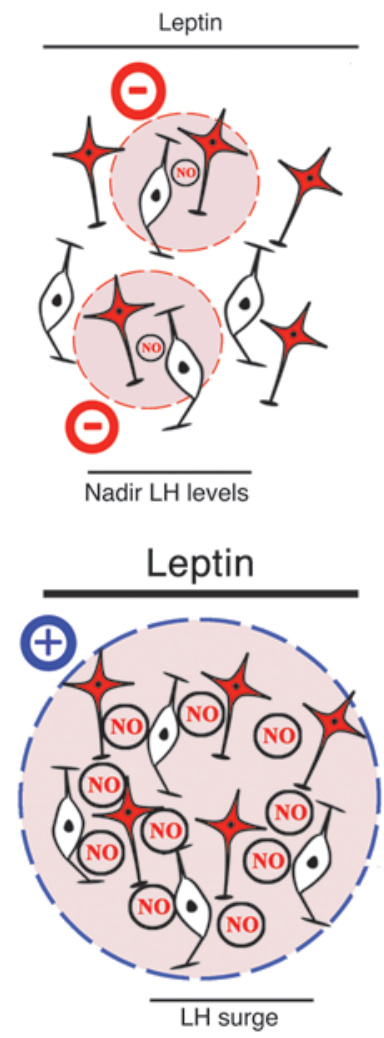

I. $\begin{gathered}\text { GnRH } \\ \text { neurons }\end{gathered} \begin{gathered}\text { nNOS } \\ \text { neurons }\end{gathered}$

\section{Figure 2}

The blockade of nNOS blunts leptin's ability to induce $\mathrm{LH}$ release. (A) nNOS activity is required for leptin-induced LH release, independently of kisspeptin/ GPR54 signaling. (B) The pharmacological inhibition of nNOS, specifically within the preoptic region (POA), is sufficient to block leptin-induced $\mathrm{LH}$ release. The diagram and the corresponding photomicrograph show the target site into which L-NAME was stereotaxically infused in the preoptic region, in which $\mathrm{GnRH}$ (green dots) and nNOS (red dots) neuronal cell bodies are intermingled. ac, anterior commissure. The asterisk in the image indicates the trajectory of the implanted needle. Scale bar: $500 \mu \mathrm{m}$. (C) Schematic representation of the hypothetical mechanisms of regulation of $\mathrm{LH}$ secretion in the absence (top panel) or presence (bottom panel) of exogenous leptin treatment in diestrus mice (see Supplemental Figure 2 for mathematical modeling). ${ }^{\star} P<0.05,{ }^{* \star} P<0.01$. tively contain the LepR, suggesting that leptin-induced LH release involves kisspeptin/GPR54 signaling (3). However, this hypothesis is somewhat controversial, since only $5 \%$ of kisspeptin neurons in the ARH have been confirmed to express the LepR (11) and the selective deletion of this receptor in kisspeptin neurons results in normal sexual maturation and continued fertility (25). To ascertain whether kisspeptin/GPR54 signaling is required for leptin-induced $\mathrm{LH}$ release in the current model, leptin was administered to Gpr54 $4^{-/}$mice and their wild-type littermates. Leptin stimulated the release of LH in both wild-type and Gpr54/- mice at diestrus within 15 minutes of its administration (Figure $2 \mathrm{~A})(n=4-5, P<0.05)$, suggesting that kisspeptin/GPR54 signaling is not required for the effects of leptin on LH release. This result is in stark contrast to that found in mice lacking Nos1, in which leptin did not trigger an increase in LH levels (Figure $2 \mathrm{~A})(n=4-5, P=0.93)$. To confirm that NO signaling is involved in the leptin-induced $\mathrm{LH}$ release, wild-type mice were injected i.p. with a NOS inhibitor, NG-nitro-L-arginine methyl ester hydrochloride (L-NAME), 3 hours prior to leptin administration. Consistent with the results obtained in Nos $1^{-1-}$ mice, leptin did not induce any increase in LH levels when coadministered with L-NAME (Figure 2B). Since we have shown previously that the chronic inhibition of nNOS activity in preoptic neurons disrupts estrous cyclicity (26), we sought to examine whether NO signaling was involved in the leptin-induced release of LH in the preoptic region by injecting L-NAME intracranially into the preoptic region prior to peripheral leptin administration. L-NAME completely suppressed the release of LH, whereas in vehi- cle-injected animals, LH levels rose in response to leptin (Figure 2B) $(n=4-6, P<0.05)$. Together, these data indicate that NO signaling, particularly within the preoptic region, is involved in the acute stimulatory effect of leptin on LH release.

Mathematical modeling of bypothalamic NO concentrations before and after leptin treatment supports a synchronizing effect. The aforementioned results could be explained if, prior to leptin treatment, NO exists as a discrete cloud restricted to the vicinity of the active nNOS neurons, whereas, after leptin treatment, greater numbers of active nNOS neurons, as indicated by P-nNOS expression, lead to a buildup of $\mathrm{NO}$ in the intervening tissue to concentrations sufficient to engage GnRH neurons located therein, leading to GnRH (and subsequent $\mathrm{LH}$ ) release.

To test the plausibility of this hypothesis, active nNOS neurons in the preoptic region were modeled as a 3-dimensional array of NO-emitting spheres (Supplemental Results and Supplemental Figure 2). From the analysis, it was concluded that the above hypothesis was fully supported, subject to 2 main conditions: first, that the number of active nNOS neurons under low-leptin conditions is half or less than that present in the fully active state achieved after leptin treatment (Figure 1C), and second, that NO was subject to a similar rate of inactivation to that found in the cerebellum (27) (see Supplemental Results). Accordingly, the model supports the idea that leptin treatment can switch the mode of operation of NO from being active only locally to being a "volume transmitter" capable of influencing cells located at a distance, irrespective of anatomical connectivity (Figure 2C). 
A

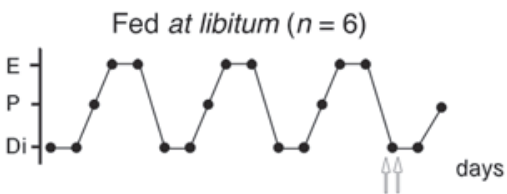

24-h fasting during diestrus $1(n=22)$
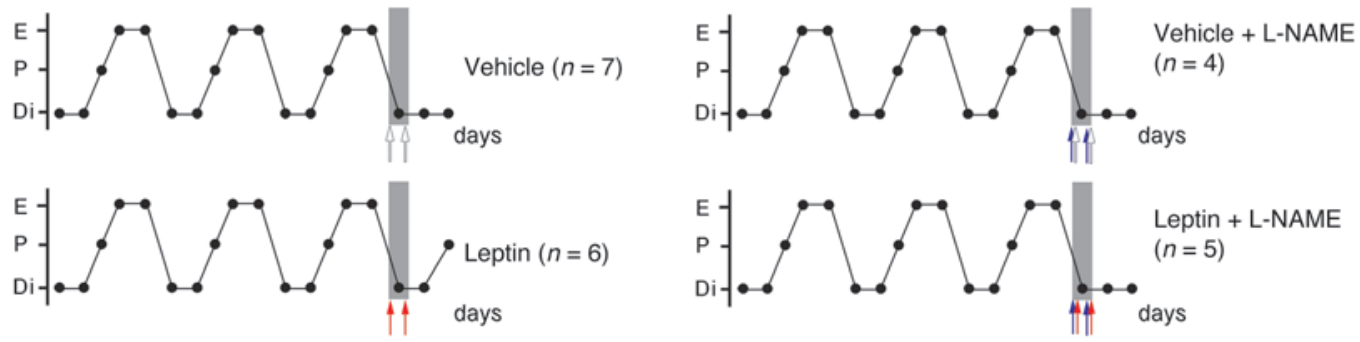

B
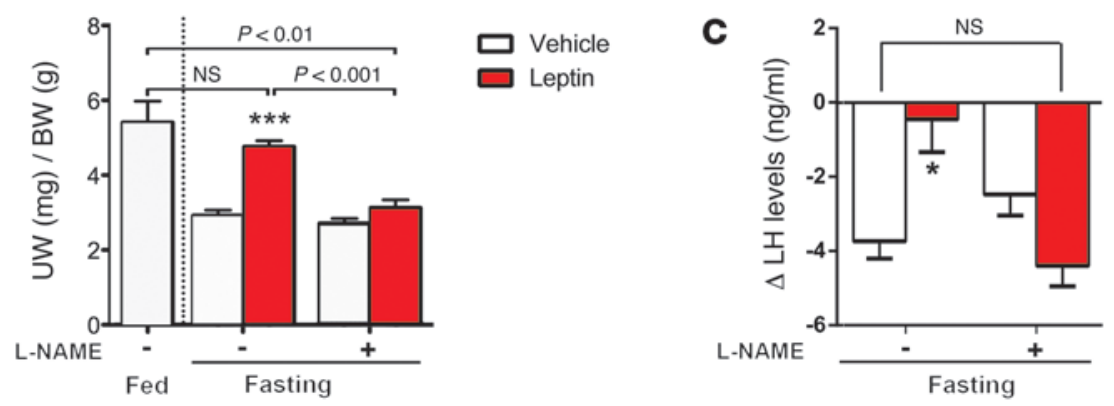

\section{Figure 3}

The pharmacological inhibition of nNOS with L-NAME prevents the rescue of the estrous cycle and LH levels by leptin in fasted mice. (A) Representative 15-day estrous cycles of animals subjected or not to 24-hour fasting in diestrus 1 three days before death (gray shadow). Mice were subjected to leptin (red arrows), L-NAME (blue arrows), or vehicle (white arrows) injection twice daily on diestrus 1 three days before death. Each circle represents 1 day. Di, diestrus; P, proestrus; E, estrus. (B) Leptin treatment in fasting mice rescued proestrous-like uterine weight (UW), whereas concomitant L-NAME injection blunted this effect. (C) Leptin treatment restores surge levels of LH in mice subjected to 24-hour fasting in diestrus 1 and killed on the expected day of proestrus, i.e., 2 days after. L-NAME treatment impedes this leptin-rescuing effect in fasting mice. ${ }^{\star} P<0.05,{ }^{* \star} P<0.001$, leptin vs. vehicle.

Leptin requires NOS activity in the neuroendocrine response to fasting. The seminal work by Ahima et al. (28) demonstrated that suppression of fertility during an acute severe fast can be rescued through bidaily administration of leptin (28). Because leptin acts, at least in part, through NO signaling to stimulate LH release, we sought to assess whether nNOS activity plays an active role in leptin-sensing during conditions of severe food deprivation. We used a modified experimental design (28), in which wild-type mice were deprived of food for 24 hours on the day of diestrus 1 and treated with either vehicle or leptin twice daily for the duration of the fast. To determine the function of nNOS activity, mice were treated with either L-NAME $(50 \mathrm{mg} / \mathrm{kg}$, i.p) or saline prior to each leptin or vehicle injection. Predictably, food deprivation for 24 hours during diestrus 1 impaired the ability of mice to enter proestrus 2 days afterward (Figure 3, A and B) and thus suppressed the preovulatory LH surge (Figure 3C), while leptin administration completely restored both estrous cyclicity and LH levels in fasted mice when compared with ad libitum fed mice (Figure 3$)(n=6-7, P=0.02)$. Remarkably, the administration of L-NAME concurrently with leptin completely abolished the ability of exogenous leptin to rescue fertility in fasting conditions (Figure 3, A-C), suggesting that NO signaling plays a role in leptin sensing during periods of food depriva- tion. Altogether, these data indicate that NO signaling is not only involved in the acute but also in the long-term stimulatory effect of leptin on the neuroendocrine reproductive axis.

nNOS signaling in the preoptic region is necessary for the recovery of sexual maturation in Lep ${ }^{o b / o b}$ mice by leptin. Chronic leptin administration to Lep ${ }^{o b / o b}$ mice is sufficient to correct the sterile phenotype (7). Here, we modified the experimental design such that each mouse received leptin ( $3 \mathrm{mg} / \mathrm{kg}$, i.p.) daily for 28 days to restore puberty in $L e p^{o b / o b}$ mice. In the first step of the experiment, Lep ${ }^{o b / o b}$ mice were crossed with Nos $1^{-/-}$mice to create a double-transgenic mouse lacking both leptin and nNOS (Nos1 $1^{-/-}$ $\left.L e p^{o b / o b}\right)$ in order to establish the necessity of NO signaling. In the second step, local inhibition of nNOS in the preoptic region was used to examine the role of NO signaling in this discrete brain area. To do this, the NOS inhibitor L-NAME was delivered chronically into the preoptic region for the duration of the leptin treatment regimen.

Nos $1^{-/-} L e p^{o b / o b}$ mice were infertile, despite a much lower initial body weight than their Nos $1^{+/+}$Lep ${ }^{o b / o b}$ littermates (Figure 4, A and E) $(n=4, P<0.01,2$-way ANOVA). Interestingly, the targeted mutation of the LepR in nNOS cells results in an obese

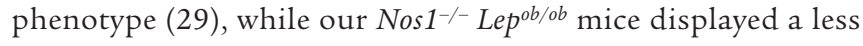


A

$$
\begin{aligned}
& \rightarrow \text { Nos } 1^{1++} \text { Lepobiab } \\
& \rightarrow \text { Nos } 1^{-+} \text {Lepobiob }
\end{aligned}
$$
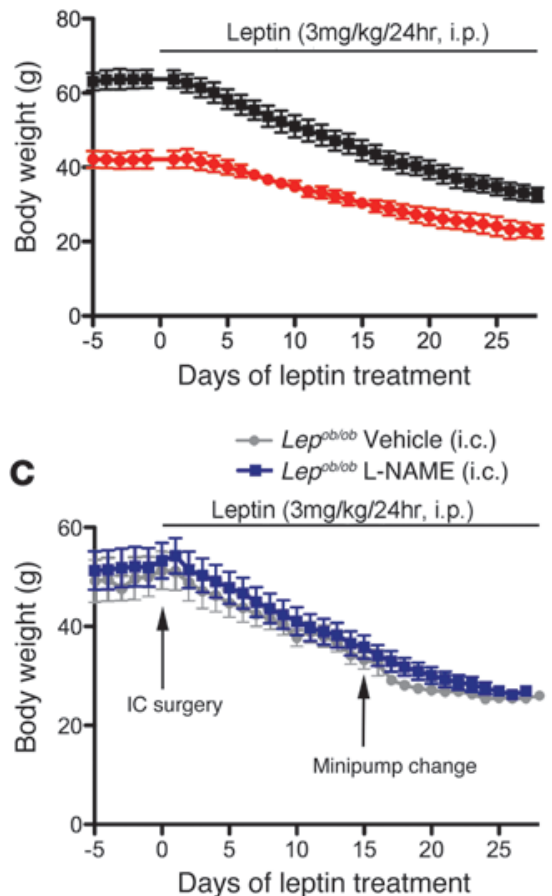

F

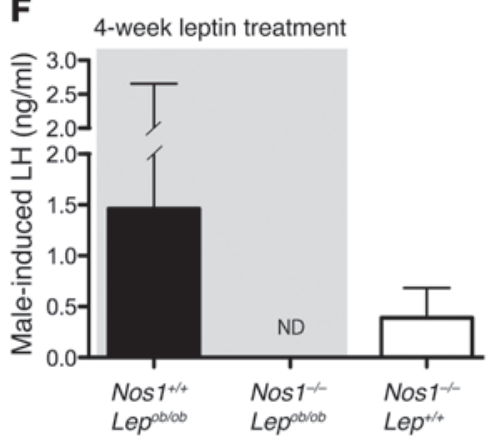

B

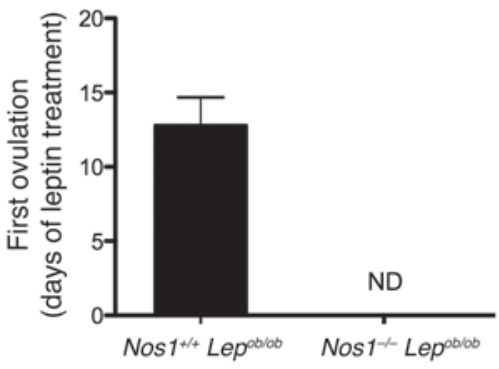

D

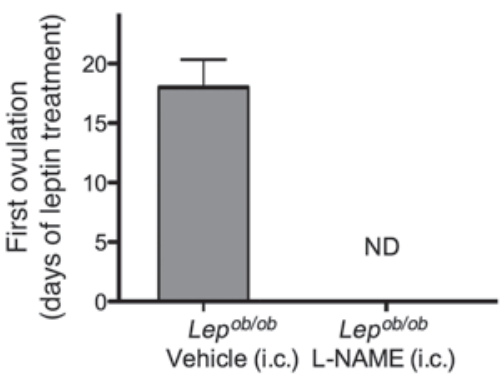

E
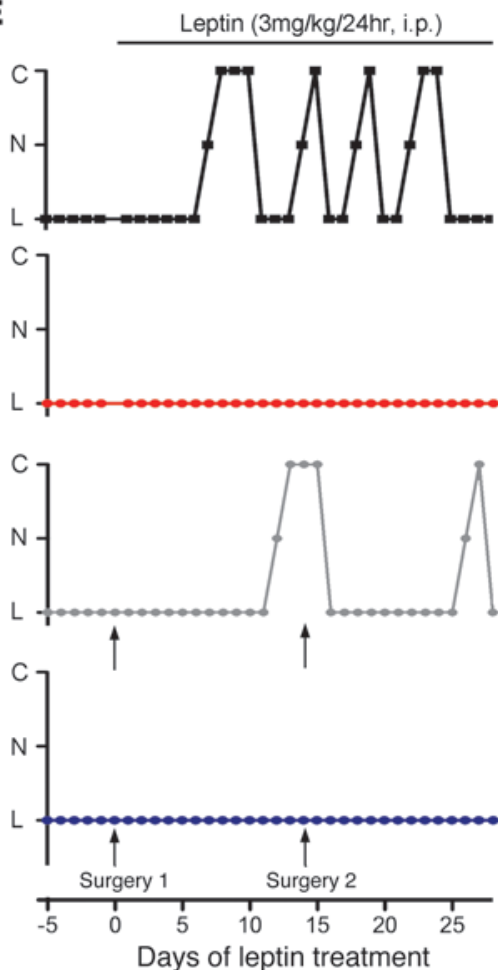

G

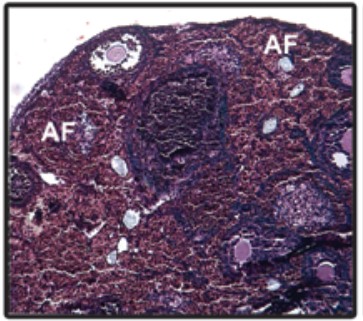

Nos $1^{+/+}$Lep

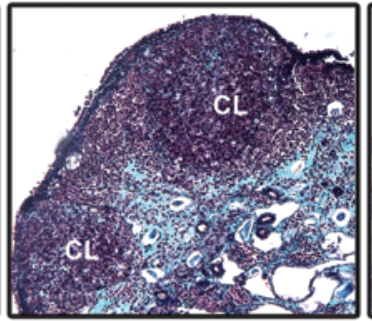

Nos1 $1^{+/+}$Lep $^{o b / o b}+$ leptin

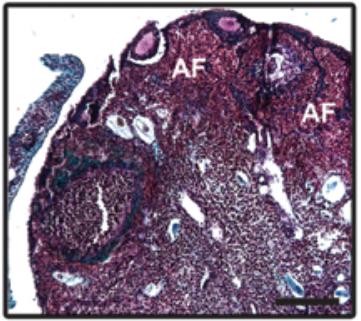

Nos $1^{-/}$Lep $^{o b / o b}+$ leptin

Figure 4

A deficiency in NO signaling renders leptin unable to induce puberty in Lep ob/ob mice. (A) Nos $1^{-/-}$Lep ${ }^{o b / o b}$ mice displayed a lower body weight than $\mathrm{Nos}^{+/+}$Lepob/ob littermates prior to the leptin regimen, although both groups lost weight with leptin treatment. (B) Nos $1^{-/-}$Lep ${ }^{o b / o b}$ mice never underwent first vaginal estrus. ND, not detected. (C) No difference in body weight was observed between Lepob/ob mice infused with either vehicle or L-NAME, although both groups responded to leptin with a decrease in body weight. (D) The Lepob/ob mice treated chronically with L-NAME never demonstrated first vaginal estrus. (E) Blockade of nNOS in Lepob/ob mice, either by genetic or pharmacologic means, resulted in a lack of estrous cyclicity, while this was corrected in control mice. C, cornified (estrus); N, nucleated (proestrus); L, lymphocytic (diestrus). (F) Blockade of nNOS in Lepob/ob mice leads to nondetectable levels of LH. Nos $1^{+/+}$Lepob/ob and Nos $1^{-/-} \mathrm{Lep}^{+/+}$mice showed partial to full surge-like LH levels following exposure to male odor. (G) Ovarian sections from Nos1+/+ Lepob/ob mice with no leptin treatment, following 28 days of leptin treatment, and $\mathrm{Nos}^{-1-}$ Lepob/ob mice, following 28 days of leptin treatment. Note the presence of corpora lutea $(\mathrm{CL})$ in Nos $1^{+/+}$Lep ob/ob mice treated with leptin. Scale bar: $100 \mu \mathrm{m}$. AF, atretic follicles; i.c., intracranial.

dramatic obese phenotype, thus raising the possibility that nNOS neurons, which are not leptin sensitive, are also involved in energy homeostasis. Predictably, the mice incurred substantial weight loss during the leptin regimen (Figure 4A). Pubertal activation was never detected in $N o s 1^{-/-} L e p^{o b / o b}$ mice, while the first estrous cycle occurred 13 days from the start of the leptin regimen in $\mathrm{Nos}^{+/+} \mathrm{Lep}^{o b / o b}$ littermates and remained variable thereafter, typically lasting 4 to 5 days (Figure 4, B and E). The Nos $1^{-/-}$single-mutant (Nos $1^{-/-} \mathrm{Lep}^{+/+}$) mice demonstrated an ovu- latory pattern, as reported in other studies $(15,30)$, suggesting that the lack of nNOS alone is not responsible for the continued infertility of $\mathrm{Nos}^{-/-}$Lep ${ }^{o b / o b}$ mice.

Three to five days prior to the end of the leptin regimen, on the day of diestrus 1 , females were placed for 62 hours in a cage that had previously held a sexually experienced male. This experimental protocol has been shown previously to induce a natural peak of LH release, necessary for ovulation in cycling females (31). Strikingly,

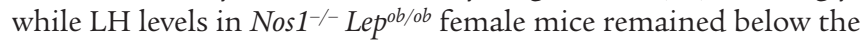


A

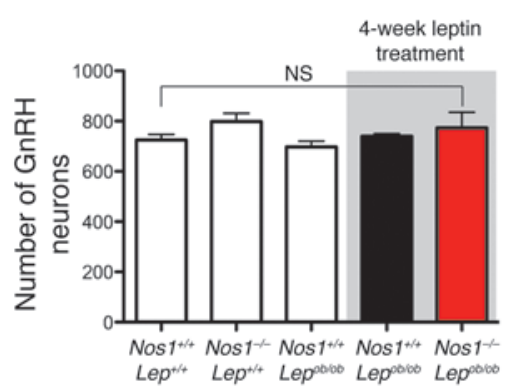

B

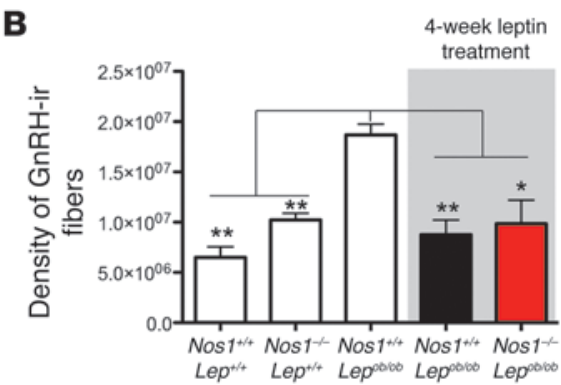

Figure 5

nNOS deficiency does not alter $\mathrm{GnRH}$ expression in $\mathrm{Lep}^{+/+}$and Lepob/ob mice. (A) The number of $\mathrm{GnRH}$ neurons in the preoptic region and (B and $\mathbf{C}$ ) the density of $\mathrm{GnRH}$-immunoreactive (ir, green) fibers in the median eminence. Interestingly, the $\mathrm{Nos}^{+/+}$Lep ob/ob mice showed an increased $\mathrm{GnRH}$ immunoreactivity, while that of $\mathrm{Nos} 1^{-/-}$ Lep ob/ob and $\mathrm{Nos}^{\mathrm{1+/}}$ Lep $^{o b / o b}$ female mice treated with leptin was equivalent to that of wild-type and $\mathrm{Nos}^{-/-} \mathrm{Lep}^{+/+}$mutant mice.

Scale bar: $200 \mu \mathrm{m} .{ }^{*} P<0.05,{ }^{\star \star} P<0.01$.
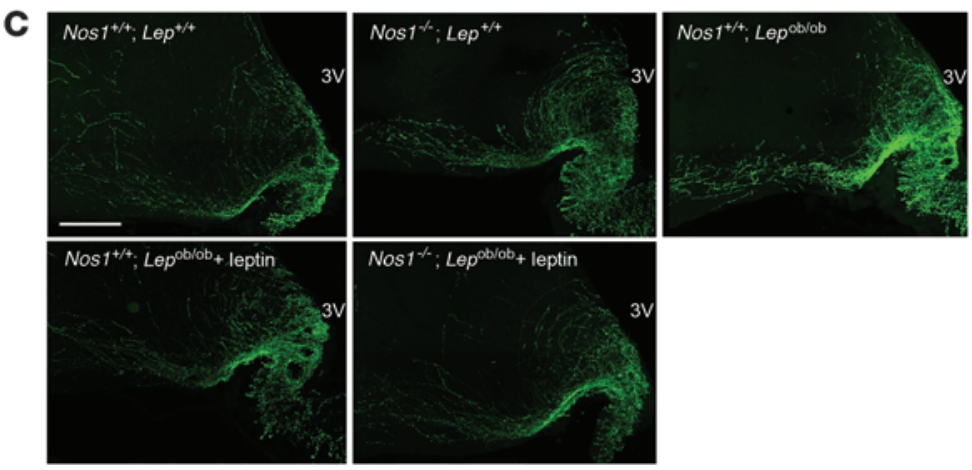

limit of detection, $\mathrm{Nos}^{+/ /+} \mathrm{Lep} \mathrm{p}^{o b / o b}$ females displayed a quintessential surge in LH levels (Figure 4F). Importantly, Nos1-/- $\mathrm{Lep}^{+/+}$littermates demonstrated detectable basal LH levels as well as an increase in plasma LH following exposure to male odors, as described above $(n=4,0.39 \pm 0.29 \mathrm{ng} / \mathrm{ml}$ after exposure to male odor vs. $0.13 \pm 0.014$ $\mathrm{ng} / \mathrm{ml}$ under basal conditions, $P=0.05$ ), providing evidence that the lack of LH release in $\mathrm{Nos}^{-/-}$Lep ${ }^{o b / o b}$ females after the leptin regimen was not due to the Nos $1^{-/-}$mutation but rather to the impairment of leptin signal transmission to $\mathrm{GnRH}$ neurons via nNOS cells. At the gonadal level, the presence of corpora lutea was noted in $\mathrm{Nos}^{+/+} \mathrm{Lep}^{o b / o b}$ females following the leptin regimen, demonstrating that $\mathrm{Nos}^{+/+}{ }^{+}$Lep ${ }^{o b / o b}$ females had mature ovaries and had undergone ovulation, while the ovaries of Nos $1^{-/-}$Lep $^{o b / o b}$ females

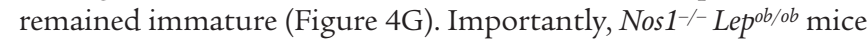
did not show any developmental alteration of the GnRH system, either with respect to the number of GnRH neurons in the preoptic region or with respect to the innervation of the median eminence, when compared with the other genotypes (Figure 5). Lepob/ob female mice without leptin treatment had dense GnRH-immunoreactive fibers within the median eminence, as previously described (25), while leptin restored GnRH-immunoreactive fibers to wild-type levels, suggesting a problem in transport and/or release of the GnRH peptide in $L e p^{o b / o b}$ animals, likely contributing to the infer-

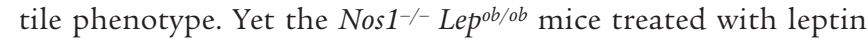
maintained normal GnRH-immunoreactive fibers at the median eminence, demonstrating that their continuing infertile phenotype is not likely to be attributed to a blockade of the GnRH peptide within the nerve terminals (Figure 5, B and C).

To further assess the role of NO signaling in the preoptic region, $L e p^{o b / o b}$ mice were given a chronic infusion of L-NAME directly into the preoptic region in conjunction with peripheral leptin administration. Remarkably, Lep ${ }^{o b / o b}$ mice treated with L-NAME phenocopied Nos1 $1^{-/}$Lepob/ob mice, in which leptin did not induce sexual maturation but did decrease body weight, while vehicle-infused animals showed their first estrus 16 days from the start of leptin treatment and recovered estrous cyclicity (Figure 4, C and D), providing further evidence of the dissociation between leptin's influence on reproduction and metabolism (25). Furthermore, at the end of the treatment regimen, all vehicle-infused Lep ${ }^{o b / o b}$ mice had detectable levels of plasma LH, similar to basal LH levels in control wild-type littermates $\left(n=3-6,0.10 \pm 0.01 \mathrm{ng} / \mathrm{ml}\right.$ in $\mathrm{Lep}^{+/+}$and $L e p^{o b /+}$ mice vs. $0.15 \pm 0.07 \mathrm{ng} / \mathrm{ml}$ in vehicle-infused Lep $p^{o b / o b}$ mice, $P=0.29$ ), while LH levels remained below the limit of detection in all animals in the L-NAME-infused group $(n=4)$. Together, these data suggest that leptin, acting through NO signaling particularly within the preoptic region, is critical for the progression of sexual maturation in leptin-deficient mice.

LepR signaling within the preoptic region controls basal LH secretion. To further study the physiological relevance of the LepR signaling in the preoptic region, we used intracranial injections of the TATCre fusion protein, whose cellular uptake is enhanced compared with Cre recombinase (32), into the preoptic region of female mice (Supplemental Figure 3) to target neurons in Leprflfl mice. Control experiments with $t d$ Tomato $^{f / /+}$ reporter mice showed that a single injection of TAT-Cre into the preoptic region caused gene recombination in neurons of this region, including those expressing nNOS, but not in other long-form LepR-expressing (LepRb-expressing) brain areas, such as the ARH and the ventral premammillary nucleus (PMv) (Supplemental Figure 3). Control experiments showed that phosphorylation of STAT3 induced by peripheral leptin administration was selectively blunted in the preoptic region of Leprfl/fl mice, while it was retained in other LepRexpressing regions of the hypothalamus (Figure 6A). This selective inhibition of LepR expression in the preoptic region that did not alter body weight (Figure 6B) led to a significant increase in uterine weight (Figure 6C) and basal LH serum levels in diestrous mice (Figure 6D) $(n=9-10,2$-way ANOVA, $P<0.05)$. In contrast, 15 -minute exogenous leptin treatment failed to promote further 
A
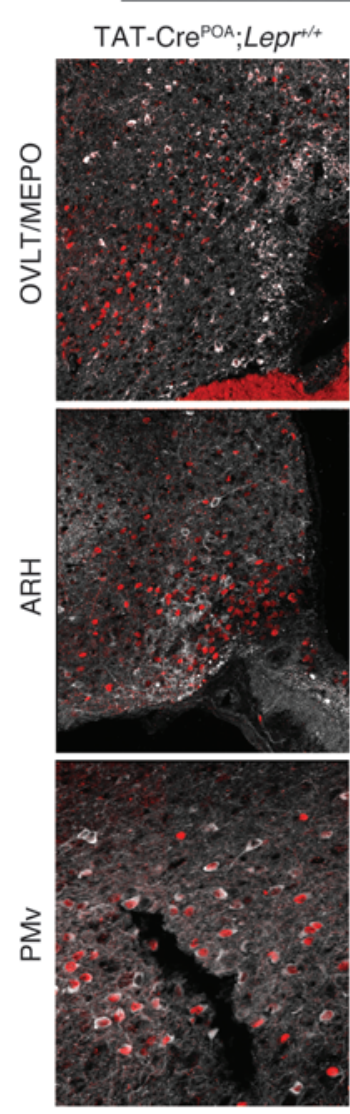

Leptin (i.p.)
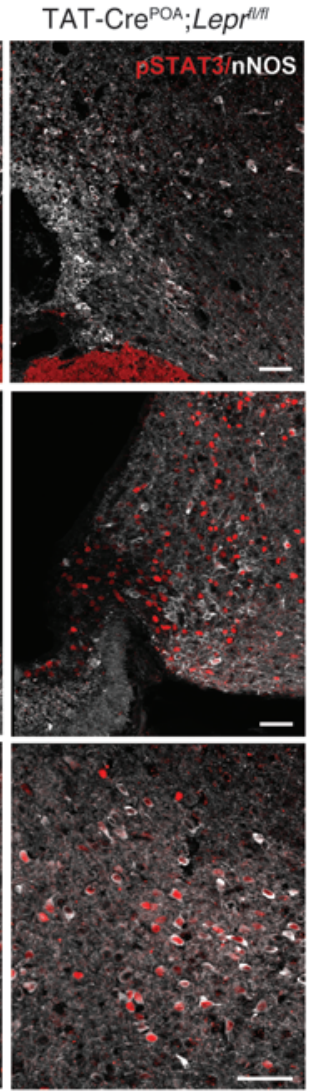

B
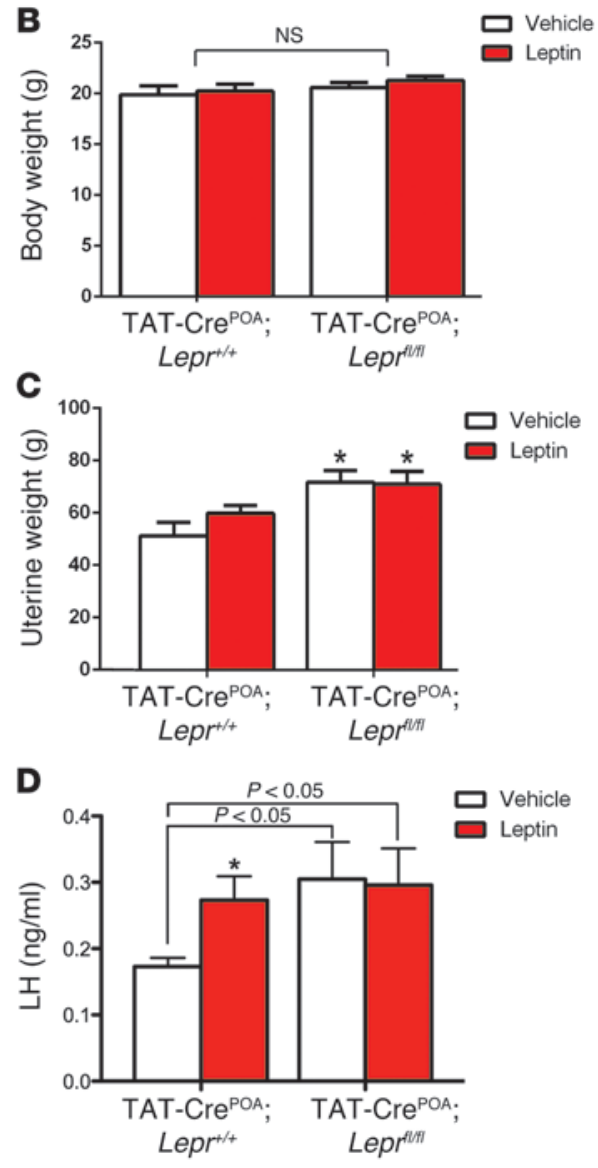

Figure 6

Site-specific deletion of LepR disrupts basal LH levels in female mice. (A) Bilateral injections of TAT-Cre protein into the OVLT/MEPO prevented P-STAT3 45 minutes following peripheral leptin injection in the preoptic region (POA) of Lepr ${ }^{f / f l}$, but not in Lepr ${ }^{+/+}$, littermates. However, leptin was still able to induce P-STAT3 in caudal areas of the hypothalamus, such as the ARH and PMv, in TAT-Cre ${ }^{\text {POA }}$ Lepr $^{\text {flffl }}$ mice. Scale bar: $200 \mu$ m. (B) Body weight did not differ between TAT-Cre ${ }^{\mathrm{POA}} \mathrm{Lepr}^{+/+}$and TAT-Cre ${ }^{\mathrm{POA}}$ Lepr $^{\text {fl/fl }}$ mice. (C) Lack of leptin signaling in the OVLT/MEPO resulted in higher uterine weight in TAT-Cre ${ }^{\mathrm{POA}}$ Lepr $^{\text {flfl }}$ mice when compared with that of TAT-Cre-injected wild-type littermates. (D) Strikingly, basal levels of LH were increased in females lacking LepR signaling in the preoptic region when compared with those of wild-type mice injected with TAT-Cre. When injected with leptin, TAT-Cre ${ }^{\mathrm{POA}}$ Lepriflif mice were unable to respond further with a rise in LH levels. Scale bar: $50 \mu \mathrm{m}$. ${ }^{*} P<0.05$.

increases in LH levels in these mice (Figure 6D) $(n=9-10,2$-way ANOVA, $P=0.35$ ). Together, these data demonstrate that LepR expression in the preoptic region plays an active role in the control of basal GnRH/LH secretion.

\section{Discussion}

The connection between metabolic homeostasis and reproductive competence has been documented extensively over many decades, yet with the rapid increase in the rates of obesity and diabetes and the subsequent deleterious effects on reproduction, the need to investigate the crosstalk between metabolism and reproduction has become more urgent. In this study, we report that nNOS neurons, in particular those residing within the preoptic region, are an integral component of leptin action on the neuroendocrine reproductive axis. Leptin promoted the rapid phosphorylation of the catalytic subunit of the nNOS protein within the preoptic region, an event associated with a rise in peripheral LH from nadir levels. Genetic deletion as well as pharmacological inhibition of nNOS prevented leptin-induced LH release. Remarkably, this effect appeared independent of kisspeptin/GPR54 signaling. Leptin-deficient mice bearing a null mutation in the Nos 1 gene or exposed to continuous nNOS inhibition failed to undergo sexual maturation in response to chronic leptin administration. Finally, we have provided evidence that LepRb expression within the preoptic region may play an active role in the control of basal GnRH/LH secretion. Together, these results demonstrate that NO signaling facilitates leptin action on reproduction and establishes the preoptic region as a novel site for the integration of leptin signaling on the GnRH neural network.

$\mathrm{NO}$ is a freely diffusible neurotransmitter, its biological effects being regulated by the catalytic properties of the nNOS enzyme, including its rate of inactivation and distance from its source (33-35). The preoptic region of the hypothalamus is one of the major sites for the expression of nNOS within the basal forebrain $(36,37)$, in which the release of $\mathrm{NO}$ has been linked to the secretion of $\mathrm{GnRH}$ and stimulation of the preovulatory surge of $\mathrm{GnRH} / \mathrm{LH}(15,38-40)$. 
The importance for nNOS activity in reproductive functioning is highlighted by the detrimental effects on fertility in nNOS-deficient female mice, ranging from sporadic ovulation and blunted preovulatory LH secretion to complete hypothalamic hypogonadism (15, $30,41)$. Intriguingly, nNOS neurons within the preoptic region have been shown to be key integrators of neural signals involved in reproduction $(15,39,42,43)$, in which the local activation of nNOS and subsequent production of $\mathrm{NO}$ exert a tonic inhibitory tone on surrounding GnRH neurons $(14,15)$. Recently, the peripheral metabolic hormone leptin has also been found to directly activate nNOS neurons (16); in this study, it has been found to induce the phosphorylation of nNOS within the preoptic region. Moreover, the targeted deletion of LepR in nNOS neurons has a profound effect on energy balance, providing evidence that nNOS neurons are crucial in the integration of metabolic signals (29). Since mice deficient in nNOS are insensitive to the stimulatory effects of leptin on GnRH/ LH secretion and the directed inhibition of nNOS in wild-type mice blunts leptin action, we extended the finding that nNOS neurons are involved in the coordination of metabolic signals and provide the first evidence that NO signaling within the preoptic region is critical to leptin's effect on the reproductive axis.

To evaluate the specific role of LepR signaling in the preoptic region, we used stereotaxic techniques to deliver a TAT-Cre recombinant protein to LepR floxed mice. The directed deletion of LepR within the OVLT/MEPO, the site in which leptin activates nNOS (16), increased basal LH release, suggesting that a minimal amount of leptin signaling in the preoptic region is required for regular basal GnRH secretion. Indeed, it appears that leptin exerts a tonic inhibitory effect on $\mathrm{GnRH} / \mathrm{LH}$ secretion, an effect strikingly similar to action of $\mathrm{NO}$ transmission on $\mathrm{GnRH}$ neurons during the estrogen-mediated negative feedback phase (15). Thus, it is tempting to speculate that LepR signaling through NO transmission is mediating this effect. Furthermore, exogenous administration of leptin fails to further promote $\mathrm{LH}$ secretion, indicating that POA LepR signaling is involved in the coordination of leptin's stimulatory effect. One caveat to note is that the use of intracranial injections inherently provides variability and heterogeneity in injection sizes, injection sites, and leakage of the TAT-Cre protein into surrounding nuclei. However, LepR functioning appears completely undisturbed in caudal parts of the hypothalamus, and the LH profile remains consistent within groups, and thus, we are confident that the effects we observed are primarily mediated through knockdown of LepRbs within the preoptic region.

Previous studies have demonstrated that states of negative energy balance, in which leptin levels are low, result in decreased LH levels and the suppression of the estrous cycle, while leptin treatment restores fertility $(28,44-46)$. Although leptin is considered stimulatory in nature, it is the fall in leptin levels that is the critical signal required for the organism to sense acute and long-term changes in energy balance and initiate a neuroendocrine response (28). Interestingly, in our fasting paradigm, leptin actively restored LH levels, while the inhibition of nNOS activity prior to leptin treatment rendered the neuroendocrine reproductive axis unable to sense the increase in leptin levels. Thus, the presence of nNOS activity and subsequent volume transmission of $\mathrm{NO}$ appear to be necessary for sensing the changes in leptin levels to relay to GnRH neurons, a scenario that our computer modeling showed to be plausible.

In addition to modulating leptin signaling, nNOS neurons also act as an interface for kisspeptin signaling (15). However, targeted deletion of the LepR in kisspeptin neurons does not disrupt fertil- ity $(25,47)$, and the selective reactivation of the LepR in kisspeptin neurons in mice otherwise null for the LepR (LepR-null mice) is not sufficient to promote sexual maturation (47). In agreement, in our Gpr54 $4^{--}$mouse model, leptin evoked a rise in LH levels, which was not mitigated by the complete absence of kisspeptin/GPR54 signaling, suggesting that leptin does not require GPR54 signaling to stimulate the neuroendocrine reproductive axis.

The lack of pubertal activation in Lep ${ }^{o b / o b}$ mice in which nNOS was site specifically inhibited argues for the importance of leptin signaling within the preoptic region in the onset of the neuroendocrine control of fertility. However, nNOS is also expressed in various other LepR-containing regions of the hypothalamus, making it impossible to exclude the involvement of NO signaling originating from regions other than the preoptic. Among these leptin-sensitive regions is the ventral portion of the $\operatorname{PMv}(16,17,29,48)$, another hypothalamic area involved in the neuroendocrine regulation of fertility $(25,29)$, in which the majority of the neurons that express nNOS are also capable of sensing leptin $(16,29)$. Intriguingly, leptin-sensitive PMv neurons are also glutamatergic and project to the preoptic region $(17,25)$. Since most of the nNOS neurons in the preoptic region express the NMDA receptor (26), which is involved in the onset of puberty (49) and regulates nNOS activity $(19,26,50$, $51)$, it is tempting to speculate that glutamatergic neurons of the PMv morphologically and functionally interact with nNOS neurons of the preoptic region to regulate the activity of GnRH neurons, thus synchronizing the effects of leptin in the 2 regions. Curiously, cre-mediated excision of the LepR in glutamatergic neurons results in no striking metabolic or reproductive phenotype $(52,53)$, suggesting that leptin signaling through glutamate is not required for fertility. Yet, the reactivation of the LepR in mice otherwise null for the LepR within the PMv, which houses predominantly glutamatergic neurons, is sufficient to rescue fertility (25). Thus, the coordination between leptin-sensing glutamatergic PMv neurons and preoptic nNOS neurons may nonetheless occur in normal conditions and potentially regulate GnRH release.

Consistent with our model, female mice with a selective deletion of the LepR in nNOS neurons demonstrate a substantial delay in the onset of puberty (29). The fact that reproductive capacity remained uncompromised in these mice during adulthood presumably points to the redundancy in the reproductive axis (29). The deletion of the LepR in nNOS neurons occurred during early development and likely allowed for the generation of compensatory changes. Consistent with this hypothesis, functional redundancies in the neuroendocrine reproductive axis have been demonstrated in several cases, including $\mathrm{GnRH}(54,55)$ and kisspeptin neurons (23). As reproduction is such a critical and energy-consuming process, redundancies in the metabolic pathway controlling reproduction would ensure the survival of the species. In the present study, experiments were designed to inhibit nNOS activity and LepRb expression exclusively during adulthood, precluding the development of compensatory mechanisms, as seen in both the metabolic and reproductive neural circuitry $(23,56)$. In the future, a nNOS-inducible cre mouse would be needed to clarify the role for leptin signaling in these neurons during development and adulthood.

The directed inhibition of nNOS in obese leptin-deficient females did not prevent leptin-induced weight loss during the 4-week leptin regimen. Yet the progression through puberty was not observed despite the substantial decrease in body weigh in these mice. Our study, in conjunction with data from Elias and colleagues demonstrating that the selective reactivation of the 
LepR in LepR-null mice restores fertility but does not rescue body weight (25), provides compelling evidence that leptin can act through multiple independent pathways to influence metabolism and reproductive fecundity. It should be noted, however, that the termination of our experiment was 4 weeks from the start of the leptin regimen, and the possibility remains that the leptin-deficient $\mathrm{Nos}^{-/-}$mice and the Lepob/ob mice treated with the nNOS inhibitor may have regained reproductive functioning with further time on leptin treatment.

In the present study, we show that, in addition to regulating estrogen-dependent neural inputs, such as kisspeptidergic signals, the same population of NO-synthesizing neurons also sense leptin, thereby transmitting information regarding peripheral energy stores to GnRH neurons. Together, these data give rise to the provocative idea that nNOS neurons of the OVLT/MEPO are a vital cell population for the rapid integration and transmission of both gonadal and metabolic signals in the neuroendocrine brain.

\section{Methods}

Animals. All experiments were carried out in accordance with the European Communities Council Directive of November 24, 1986 (86/609/ EEC), and French bylaws regarding mammalian research and were approved by the Institutional Animal Care and Use Committee of The Saban Research Institute and the University of Lille. Experiments were performed on adult (3- to 6-month-old) female C57BL/6J mice (Charles River Laboratories), Nos1-null (Nos1 1/-, B6.129S4-Nos1tm1Plh/J) mice (30), Lep-null (Lep ${ }^{o b / o b}$, B6.V-Lepob/J) mice (Jax mice; Jackson Laboratory),

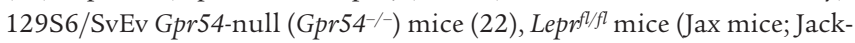
son Laboratories), and their respective wild-type littermates. Nos $1^{-/-}$ $L e p^{o b / o b}$ mice were generated in our animal facility by crossing $\mathrm{Nos}^{-1^{-+}}$

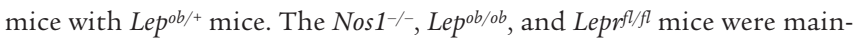
tained on a C57B6/J background, while the Gpr54 $4^{-/-}$mice were maintained on a mixed 129/SV background.

Drugs. Recombinant murine leptin ( $3 \mathrm{mg} / \mathrm{kg}$, i.p.) and the NOS inhibitor L-NAME $(50 \mathrm{mg} / \mathrm{kg}$, i.p.; $5 \mathrm{mM}$ intracranially) were purchased from Peprotech and Calbiochem, respectively.

Immunohistochemistry. The detection of nNOS, P-nNOS, and P-STAT3 was carried out using protocols that we have described previously $(15,18)$. Detailed methods are provided in the Supplemental Methods.

Western blot analyses. The detection of P-nNOS and $\mathrm{nNOS}$ by Western blotting was carried out as described previously (15).

Stereotaxic surgery. L-NAME $(5 \mathrm{mM})$ or sterile saline was infused into the preoptic region (coordinates from bregma: $+0.5 \mathrm{~mm}$ anteroposterior, \pm 0.2 $\mathrm{mm}$ lateral, $-5.3 \mathrm{~mm}$ in depth) of mice in vivo using a Hamilton syringe or infusion cannula connected to a subcutaneously implanted osmotic minipump for acute and chronic infusion, respectively. The TAT-Cre protein was injected bilaterally into floxed animals at the same coordinates. Detailed methods are provided in the Supplemental Methods.

Mathematical model. Detailed methods are provided in the Supplemental Methods.

TAT-Cre delivery. A TAT-Cre fusion protein produced, as detailed previously $(32,57)$, was stereotaxically infused into the preoptic region $(300 \mathrm{nl}$ over 5 minutes at $2.1 \mathrm{mg} / \mathrm{ml} ;+0.5 \mathrm{~mm}$ anteroposterior; $0.2 \mathrm{~mm}$ mediolateral; -5.3 mm dorsoventral) of isoflurane-anesthetized $\mathrm{Lepr}^{\mathrm{l} / \mathrm{fl}}$ and $\mathrm{Lepr}^{+/+}$ 2-month-old littermates 6 days before experiments.

Plasma LH assay. Plasma LH was measured using a Rodent LH ELISA Kit (Endocrine Technologies) with a sensitivity of $0.01 \mathrm{ng} / \mathrm{ml}$ and $7 \%$ intraassay and $10 \%$ interassay coefficients of variance.

Statistics. Statistical analysis was performed using GraphPad Prism software. Bar graphs were plotted with GraphPad Prism software with the SEM. Differences between 2 groups were analyzed with an unpaired Student's $t$ test. One-way ANOVA or multivariate ANOVA followed by a Tukey post-hoc test was used to draw comparisons between 3 or more groups. $P$ values of less than 0.05 were considered to be statistically significant.

\section{Acknowledgments}

This research was supported by the NEUROBESE International Associated Laboratory (Inserm, Saban, University of Lille 2, to V. Prevot and S.G. Bouret), the Fondation pour la Recherche Médicale (Equipe FRM 2005 and DEQ20130326524, France, to V. Prevot; Régulation Métabolique to S.G. Bouret), the Agence National pour la Recherche (ANR-09-BLAN-0267, France, to V. Prevot), the EUFP7 Integrated Project (grant agreement 266408, Full4Health, to S.G. Bouret), the Biotechnology and Biological Sciences Research Council (grant BB/F01936X/1 to W. Colledge), and the NIH (grant DK84142 to S.G. Bouret). N. Bellefontaine was supported by a doctoral fellowship from the University of Lille 2 . We would like to thank Carol F. Elias for her insightful discussions about the manuscript. We would also like to thank S. Rasika for the editing of our manuscript, and Delphine Taillieu, Julien Devassine, Delphine Cappe, and Melanie Besegher (animal facility, IFR 114) for expert technical assistance.

Received for publication February 20, 2014, and accepted in revised form March 20, 2014.

Address correspondence to: Vincent Prevot, INSERM U837, Batiment Biserte, Place de Verdun, 59045 Lille cedex, France. Phone: 33.3.20.62.20.64; Fax: 33.3.20.53.85.62; E-mail: vincent.prevot@ inserm.fr.
1. Biro FM, Khoury P, Morrison JA. Influence of obesity on timing of puberty. Int J Androl. 2006; 29(1):272-277.

2. Friedman CI, Kim MH. Obesity and its effect on reproductive function. Clin Obstet Gynecol. 1985; 28(3):645-663.

3. Elias CF. Leptin action in pubertal development: recent advances and unanswered questions. Trends Endocrinol Metab. 2012;23(1):9-15.

4. Ahima RS, Dushay J, Flier SN, Prabakaran D, Flier JS. Leptin accelerates the onset of puberty in normal female mice. J Clin Invest. 1997;99(3):391-395.

5. Yura S, et al. Accelerated puberty and late-onset hypothalamic hypogonadism in female transgenic skinny mice overexpressing leptin. J Clin Invest. 2000;105(6):749-755.

6. Montague CT, et al. Congenital leptin deficiency is associated with severe early-onset obesity in humans. Nature. 1997;387(6636):903-908.

7. Chehab FF, Lim ME, Lu R. Correction of the sterility defect in homozygous obese female mice by treatment with the human recombinant leptin. Nat Genet. 1996;12(3):318-320.

8. Farooqi IS, et al. Effects of recombinant leptin therapy in a child with congenital leptin deficiency. N Engl J Med. 1999;341(12):879-884.

9. Quennell JH, et al. Leptin indirectly regulates gonadotropin-releasing hormone neuronal function. Endocrinology. 2009;150(6):2805-2812.

10. Sullivan SD, DeFazio RA, Moenter SM. Metabolic regulation of fertility through presynaptic and postsynaptic signaling to gonadotropin-releasing hormone neurons. J Neurosci. 2003;23(24):8578-8585.

11. Louis GW, et al. Molecular mapping of the neural pathways linking leptin to the neuroendocrine reproductive axis. Endocrinology. 2011;152(6):2302-2310.
12. Boehning D, Snyder SH. Novel neural modulators. Annu Rev Neurosci. 2003;26:105-131.

13. Bellefontaine $\mathrm{N}$, et al. Nitric oxide as key mediator of neuron-to-neuron and endothelia-to-glia communication involved in the neuroendocrine control of reproduction. Neuroendocrinology. 2011;93(2):74-89.

14. Clasadonte J, Poulain P, Beauvillain JC, Prevot V. Activation of neuronal nitric oxide release inhibits spontaneous firing in adult gonadotropin-releasing hormone neurons: a possible local synchronizing signal. Endocrinology. 2008;149(2):587-596.

15. Hanchate NK, et al. Kisspeptin-GPR54 signaling in mouse NO-synthesizing neurons participates in the hypothalamic control of ovulation. J Neurosci. 2012;32(3):932-945.

16. Donato J, Donato J Jr, Frazao R, Fukuda M, Vianna CR, Elias CF. Leptin induces phosphory- 
lation of neuronal nitric oxide synthase in defined hypothalamic neurons. Endocrinology. 2010; 151(11):5415-5427.

17. Leshan RL, et al. Direct innervation of GnRH neurons by metabolic- and sexual odorantsensing leptin receptor neurons in the hypothalamic ventral premammillary nucleus. J Neurosci. 2009;29(10):3138-3147.

18. Caron E, Sachot C, Prevot V, Bouret SG. Distribution of leptin-sensitive cells in the postnatal and adult mouse brain. J Comp Neurol. 2010;518(4):459-476.

19. Parkash J, et al. Phosphorylation of N-methyl-Daspartic acid receptor-associated neuronal nitric oxide synthase depends on estrogens and modulates hypothalamic nitric oxide production during the ovarian cycle. Endocrinology. 2010;151(6):2723-2735.

20. Langlet F, Mullier A, Bouret SG, Prevot V, Dehouck B. Tanycyte-like cells form a blood-cerebrospinal fluid barrier in the circumventricular organs of the mouse brain. J Comp Neurol. 2013;521(15):3389-3405.

21. Herde MK, Geist K, Campbell RE, Herbison AE. Gonadotropin-releasing hormone neurons extend complex highly branched dendritic trees outside the blood-brain barrier. Endocrinology. 2011;152(10):3832-3841.

22. Seminara SB, et al. The GPR54 gene as a regulator of puberty. N Engl J Med. 2003;349(17):1614-1627.

23. Mayer C, Boehm U. Female reproductive maturation in the absence of kisspeptin/GPR54 signaling. Nat Neurosci. 2011;14(6):704-710.

24. Lehman MN, Ladha Z, Coolen LM, Hileman SM, Connors JM, Goodman RL. Neuronal plasticity and seasonal reproduction in sheep. Eur J Neurosci. 2010;32(12):2152-2164.

25 . Donato J, et al. Leptin's effect on puberty in mice is relayed by the ventral premammillary nucleus and does not require signaling in Kiss 1 neurons. J Clin Invest. 2011;121(1):355-368.

26. d'Anglemont de Tassigny $X$, et al. Coupling of neuronal nitric oxide synthase to NMDA receptors via postsynaptic density-95 depends on estrogen and contributes to the central control of adult female reproduction. J Neurosci. 2007;27(23):6103-6114.

27. Hall CN, Garthwaite J. Inactivation of nitric oxide by rat cerebellar slices. J Physiol. 2006;577(Pt 2):549-567.

28. Ahima RS, et al. Role of leptin in the neuroendocrine response to fasting. Nature. 1996;382(6588):250-252.

29. Leshan RL, Greenwald-Yarnell M, Patterson CM, Gonzalez IE, Myers MG, Myers MG Jr. Leptin action through hypothalamic nitric oxide synthase-1-expressing neurons controls energy balance. Nat Med. 2012;18(5):820-823.

30. Huang PL, Dawson TM, Bredt DS, Snyder SH, Fishman MC. Targeted disruption of the neuronal nitric oxide synthase gene. Cell. 1993;75(7):1273-1286.

31. Bronson FH, Stetson MH. Gonadotropin release in prepubertal female mice following male expo- sure: a comparison with the adult cycle. Biol Reprod. 1973;9(5):449-459.

32. Peitz M, Pfannkuche K, Rajewsky K, Edenhofer F. Ability of the hydrophobic FGF and basic TAT peptides to promote cellular uptake of recombinant Cre recombinase: a tool for efficient genetic engineering of mammalian genomes. Proc Natl Acad Sci U S A. 2002;99(7):4489-4494.

33. Garthwaite J. Concepts of neural nitric oxidemediated transmission. Eur J Neurosci. 2008; 27(11):2783-2802.

34. Rameau GA, Chiu LY, Ziff EB. Bidirectional regulation of neuronal nitric-oxide synthase phosphorylation at serine 847 by the $\mathrm{N}$-methyl-D-aspartate receptor. J Neurosci. 2004;279(14):14307-14314.

35. Garthwaite J, Boulton CL. Nitric oxide signaling in the central nervous system. Annu Rev Physiol. 1995;57:683-706.

36. Herbison AE, Simonian SX, Norris PJ, Emson PC. Relationship of neuronal nitric oxide synthase immunoreactivity to $\mathrm{GnRH}$ neurons in the ovariectomized and intact female rat. J Neuroendocrinol. 1996;8(1):73-82.

37. Bredt DS, Glatt CE, Hwang PM, Fotuhi M, Dawson TM, Snyder SH. Nitric oxide synthase protein and mRNA are discretely localized in neuronal populations of the mammalian CNS together with NADPH diaphorase. Neuron. 1991; 7(4):615-624

38. Rettori V, Belova N, Dees WL, Nyberg CL, Gimeno M, McCann SM. Role of nitric oxide in the control of luteinizing hormone-releasing hormone release in vivo and in vitro. Proc Natl Acad Sci US A. 1993;90(21):10130-10134.

39. Bonavera JJ, Sahu A, Kalra PS, Kalra SP. Evidence that nitric oxide may mediate the ovarian steroid-induced luteinizing hormone surge: involvement of excitatory amino acids. Endocrinology. 1993;133(6):2481-2487.

40. Bonavera JJ, Sahu A, Kalra PS, Kalra SP. Evidence in support of nitric oxide (NO) involvement in the cyclic release of prolactin and LH surges. Brain Res. 1994;660(1):175-179.

41. Gyurko R, Leupen S, Huang PL. Deletion of exon 6 of the neuronal nitric oxide synthase gene in mice results in hypogonadism and infertility. Endocrinology. 2002;143(7):2767-2774.

42. Bonavera JJ, Kalra PS, Kalra SP. L-arginine/nitric oxide amplifies the magnitude and duration of the luteinizing hormone surge induced by estrogen: involvement of neuropeptide Y. Endocrinology. 1996;137(5):1956-1962

43. Pu S, Xu B, Kalra SP, Kalra PS. Evidence that gonadal steroids modulate nitric oxide efflux in the medial preoptic area: effects of N-methyl-D-aspartate and correlation with luteinizing hormone secretion. Endocrinology. 1996;137(5):1949-1955.
44. Donato J, et al. The ventral premammillary nucleus links fasting-induced changes in leptin levels and coordinated luteinizing hormone secretion. J Neurosci. 2009;29(16):5240-5250.

45. Nagatani S, Guthikonda P, Thompson RC, Tsukamura H, Maeda KI, Foster DL. Evidence for GnRH regulation by leptin: leptin administration prevents reduced pulsatile LH secretion during fasting. Neuroendocrinology. 1998;67(6):370-376.

46. Welt CK, et al. Recombinant human leptin in women with hypothalamic amenorrhea. $N$ Engl J Med. 2004;351(10):987-997.

47. Cravo RM, et al. Leptin signaling in Kiss1 neurons arises after pubertal development. PLoS One. 2013;8(3):e58698.

48. Canteras NS, Simerly RB, Swanson LW. Projections of the ventral premammillary nucleus. J Comp Neurol. 1992;324(2):195-212.

49. Urbanski HF, Ojeda SR. A role for N-methyl-Daspartate (NMDA) receptors in the control of $\mathrm{LH}$ secretion and initiation of female puberty. Endocrinology. 1990;126(3):1774-1776.

50. Garthwaite J, Charles SL, Chess-Williams R. Endothelium-derived relaxing factor release on activation of NMDA receptors suggests role as intercellular messenger in the brain. Nature. 1988; 336(6197):385-388.

51. Mahachoklertwattana P, Black SM, Kaplan SL, Bristow JD, Grumbach MM. Nitric oxide synthesized by gonadotropin-releasing hormone neurons is a mediator of N-methyl-D-aspartate (NMDA)induced GnRH secretion. Endocrinology. 1994; 135(4):1709-1712.

52. Kong D, et al. GABAergic RIP-Cre neurons in the arcuate nucleus selectively regulate energy expenditure. Cell. 2012;151(3):645-657.

53. Zuure WA, Roberts AL, Quennell JH, Anderson GM. Leptin signaling in GABA neurons, but not glutamate neurons, is required for reproductive function. J Neurosci. 2013;33(45):17874-17883.

54. Gibson MJ, Krieger DT, Charlton HM, Zimmerman EA, Silverman AJ, Perlow MJ. Mating and pregnancy can occur in genetically hypogonadal mice with preoptic area brain grafts. Science. 1984;225(4665):949-951.

55. Herbison AE, Porteous R, Pape JR, Mora JM, Hurst PR. Gonadotropin-releasing hormone neuron requirements for puberty, ovulation, and fertility. Endocrinology. 2008;149(2):597-604.

56. Luquet S, Perez FA, Hnasko TS, Palmiter RD. NPY/AgRP neurons are essential for feeding in adult mice but can be ablated in neonates. Science. 2005;310(5748):683-685.

57. Langlet F, et al. Tanycytic VEGF-A boosts bloodhypothalamus barrier plasticity and access of metabolic signals to the arcuate nucleus in response to fasting. Cell Metab. 2013;17(4):607-617. 